\title{
Statistical methods for the analysis of the characteristic curve of brass by Vickers indentation
}

\author{
S. Habibi \\ Faculty of Science and Technology, University Mustapha Stambouli of Mascara, 29000 Mascara, Algeria, \\ E-mail:habibismr@yahoo.com \\ cross $^{\text {ref }}$ http://dx.doi.org/10.5755/j01.mech.22.6.12998
}

\section{Introduction}

The instrumented indentation draws its sources from the definition of contact between two bodies. It has been the object of investigation of several authors in the field of mechanics. In its general principle, instrumented indentation test can record the displacement of the indenter, throughout the cycle of loading and unloading. Analysis of the unloading curve leads to a value of the contact depth that takes into account the actual contact between the indenter and the material. The most commonly used method for determining the modulus of elasticity and hardness by nanoindentation was proposed by Oliver and Pharr, wherein the slope of the discharge curve which is nonlinear in general was used to calculate the modulus of elasticity and provide a physically justifiable procedure for determining the depth to be used in conjunction with the indenter shape function to establish the contact area at peak load.

This article aims to study the mechanical properties of brass through experimental tests of nanoindentation. It develops an analysis of load-displacement curve by following five goals:

- determination of the contact depth, $h_{c}$;

- calculation of hardness, HIT, and elastic modulus, EIT;

- estimation of the contact stiffness, $S$;

- modelling the $S / h_{c}$ slope for different loads indentation, $P$, by linear regression by the method of least squares, to express the inverse of the contact area, $1 / A_{c}$;

- slope modelling $S / h_{c}$, depending on other variables studied EIT and HIT.

\section{Materials and experimental method}

Experimental indentation tests were conducted on films of brass deposited on glass slides using a nanoindentor instrumented MCT (Instrument CSM2-107). For each sample, at least 20 tests were carried out with maximum load of $20 \mathrm{mN}$ to $3000 \mathrm{mN}$. The indentation tests were performed with a Vickers indenter. The load is applied at a rate of $40 \mathrm{mN} / \mathrm{min}$. The maximum load is maintained for $15 \mathrm{sec}-$ onds and then gradually withdraw at a speed of $40 \mathrm{mN} / \mathrm{min}$. All curves penetration strength results were then exported and processed using the Matlab software to calculate the mechanical properties ofmaterial studied by different methods (Oliver and Pharr [1], Feng and Ngan [2, 3], Chicot and Mercier [4]). The end of each penetration defects were evaluated using an electron microscope field emission scanning Hitachi S-type $4300 \mathrm{SE} / \mathrm{N}$. The measures are estimated at $150 \mathrm{~nm}$ for the Vickers indenter [5].

\section{Results and discussion}

\subsection{Analysis of the load-displacement curve}

In an instrumented indentation test, the indent diamond is pressed to the sample surface corresponding to a maximum load value at a given depth. Simultaneously records the load and the displacement of the indenter as shown in Fig. 1

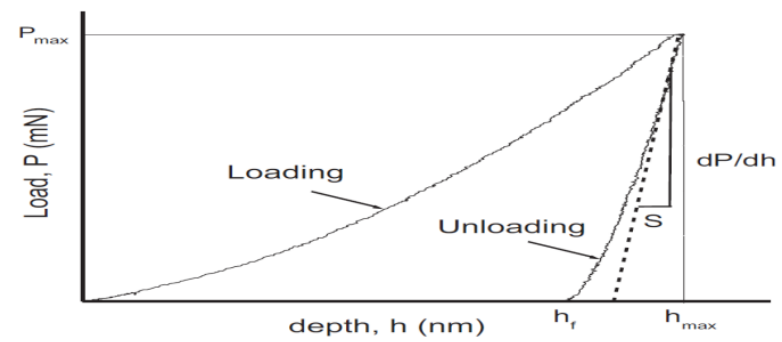

Fig. 1 Schematic representation of a loading-displacement curve obtained by nanoindentation and parameters required for the analysis [6]

The Fig. 2 shows in key locations the position of the indentor in the material.

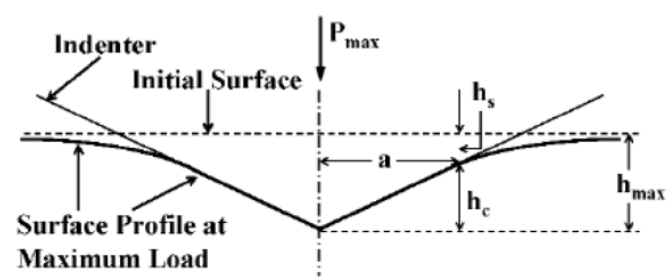

Fig. 2 Representation of the maximum indentation load geometry for ideal conical indenter [7]

$h_{\max }$ is the maximum depth reached, $h_{f}$ is the residual depthafter withdrawal of the indentor and $h_{c}$ is the contact depth used in calculating the hardness of Oliver and Pharr [1]. Fig. 2 to better see the different sizes determined by nanoindentation. Calculating $h_{c}$, wherein a parameter $\varepsilon$ is introduced to take into account the deformations of the indenter impression [8] (deflection of the sink-in surfaces) is expressed by the following relationship:

$$
h_{c}=h_{\max }-0.75 \frac{P_{\max }}{S_{u}}
$$

For pyramidal Vickers indenter geometry with four faces, the projected contact area is proportional to the square of $h_{c}$, as indicated by the following expression: 


$$
A=24.56 h_{c}^{2} .
$$

We applied the model of Oliver and Pharr [3]. The values calculated are shown in Fig. 3.

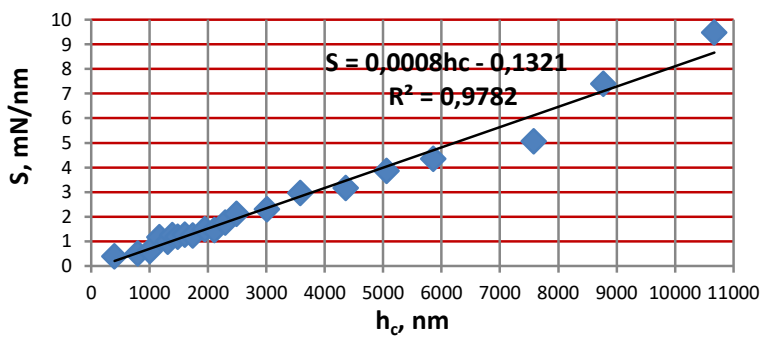

Fig. 3 Results rigidities contact vs contact depths by nanoindentation

The experimental results of the nanoindentation tests are shown in Fig. 3 relating to the 21 tests considered. The curve shows good reproducibility of the test. Following the linear regression by the method of least squares, we find a slope $\left(S / h_{c}\right)$ constant.

\subsection{Estimating the slope of the contact stiffness at the con-} tact depth

I proceeds by calculating slopes $P t_{i}=\left(S_{m} / h_{c m}\right)$ such as $i=1 \div 19$ and $m=(i+2)$, knowing that $i$ is the number of slopes estimated for 21 indentation testsachieved.

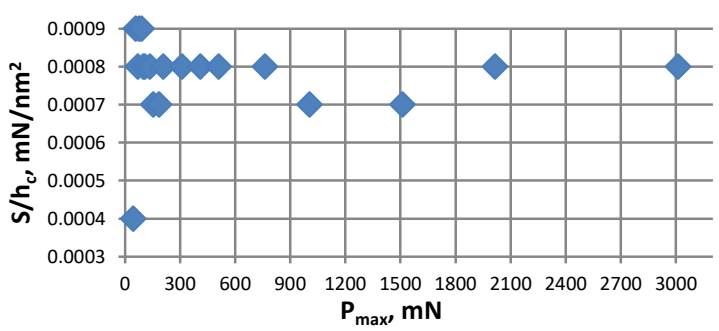

Fig. 4 Contact stiffness slope vs maximum contact depth of indentation load

According to the shape of Fig. 4, I notice a dominant trend constitutes a bearing of a set of characteristic points that are on the horizontal axis passing through the point $0.0008 \mathrm{mN} / \mathrm{nm}^{2}$, then the appearance of two other smaller bearings.

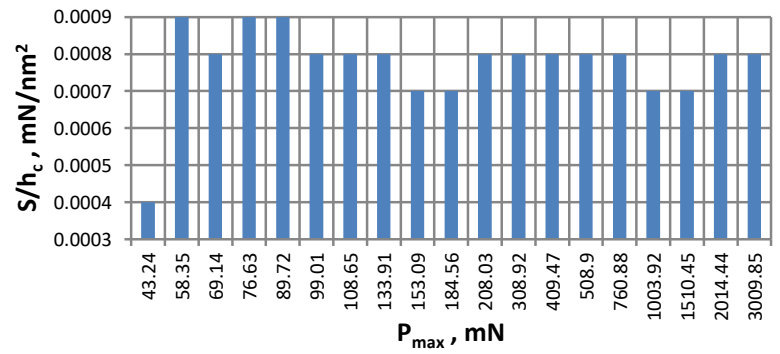

Fig. 5 Histogram of estimated slope vs maximum force indentation

The histogram of the slope $S / h_{c}$ depending on the loading force (Fig. 5) shows constant amplitude of the order of $(0.0008 \pm 0.0001) \mathrm{mN} / \mathrm{nm}^{2}$ from increasing indentation load from $58.35 \mathrm{mN}$ up $3009.85 \mathrm{mN}$. However, for the loading interval $[58.35,89.72] \mathrm{mN}$ he magnitude of the slope registers (Fig. 5) a peak $0.0001 \mathrm{mN} / \mathrm{nm}^{2}$. By against, loading intervals [153.09, 184.56] $\mathrm{mN}$ and [1003.92, 1510.45] $\mathrm{mN}$ record a slope of magnitude drop in same previous value.

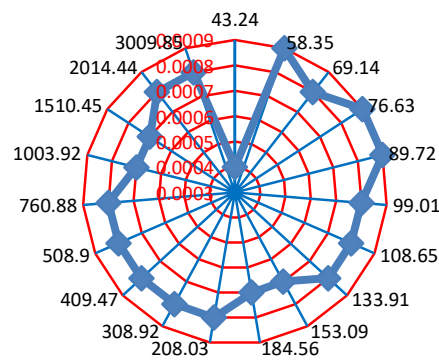

Fig. 6 Radar with nineteen loads markers

The graphical representation (Fig. 6) highlights the disparity of eleven characteristic points on the Orbit appointed $0.0008 \mathrm{GPa}$. On the other hand, three characteristic points are located on the upper orbit $0.0009 \mathrm{GPa}$ and four points on the lower orbit of $0.0007 \mathrm{GPa}$. The previous findings of Figs. 5 and 6 and are used to model the mechanical behaviour of Brass, as follows:

If $58.24 \mathrm{mN}<P_{\max }<3009.85 \mathrm{mN}$ : $\left(\frac{S / h_{c}}{P_{\max }}\right)$ is constant level.

$$
\frac{S}{h_{c}}=0.0008 P_{\max } .
$$

If $P_{\max }=\{58.35,76.63,89.72\}: S / h_{c}=0.0009 \mathrm{mN} / \mathrm{nm}^{2}$.

$$
\frac{S}{h_{c}}=0.0009 P_{\max }
$$

If $P_{\max }=\{153.09,184.56,1003.92,1510.45\}:$

$$
\frac{S}{h_{c}}=(0.0007 \pm 0.0001) P_{\max }, \mathrm{mN} / \mathrm{nm}^{2} .
$$

The magnitude of:

$$
\left.\begin{array}{l}
\left(\frac{S / h_{c}}{P_{\max }}\right)=(0.0008 \pm 0.0001) \mathrm{nm}^{-2} . \\
\frac{S}{h_{c}}=(0.0008 \pm 0.0001) \mathrm{mN} / \mathrm{nm}^{2} \\
\text { for EIT } \in[1212,1568.3] \mathrm{GPa} .
\end{array}\right\}
$$

This explains that the magnitude of the slope $\left(S / h_{c}\right)$ vs $P_{\max }$, by the use of linear regression by the method of least squares expresses the inverse of the contact area.

3.3. Confrontationslope studied with the Young's modulus

Determining the modulus of elasticity is based on the analysis of the unloading curve for the removal of the indenter is conditioned by the springback due to the elasticity of the material. The method is based on the Hertz theory 
[9] recovery by Bulychec [10] and then developed by Sneddon [11]. It provides that the slope at the beginning of discharge can be written as a function of the contact area and the reduced modulus in the form:

$$
S_{u}=\left(\frac{d P}{d h}\right)_{h=h_{\max }}=\frac{2}{\sqrt{\pi}} E_{R} \sqrt{A_{c p}} .
$$

What where the stiffness of the contact between the inventor and the material when unloading, measured at maximum penetration, $h_{\max }$. $A_{c p}$ is the projected contact area and $E_{R}$ is the reduced modulus of elasticity.The expression of the modulus of elasticity of the material is:

$$
E_{m}=\left(1-v_{m}^{2}\right)\left[\frac{2}{\sqrt{\pi}} \frac{1}{S_{u}} \sqrt{A_{c p}}-\frac{\left(1-v_{i}^{2}\right)}{E_{i}}\right]^{-1} .
$$

The graphical representations of Fig. 7, a, b shown below, include the slopes of the calculations, $\left(\frac{S}{h_{c}}\right)_{i}$ as a function of indentation modulus, EIT.

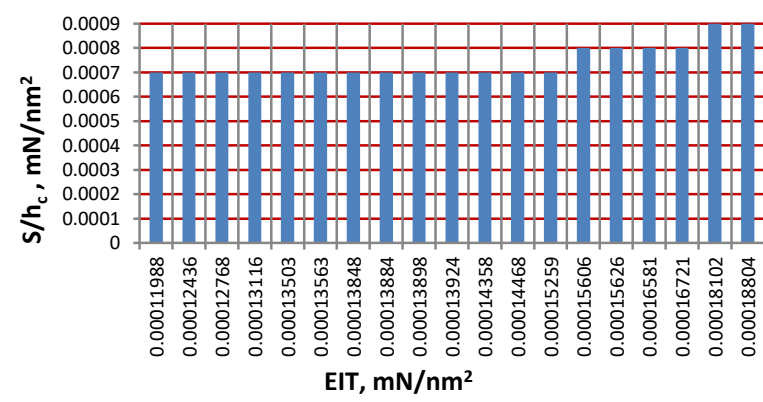

a

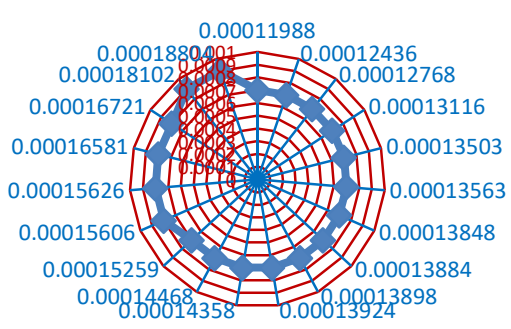

b

Fig. 7 Points caractéristiques de la pente vs EIT (a,b)

According graphical representations Fig. 7, a, b, the expression of the slopevsmodulus of elasticity, EIT, the existence of three sets of characteristic points, deposited on orbits: $\quad 0.0007 \mathrm{mN} / \mathrm{nm}^{2}, \quad 0.0008 \mathrm{mN} / \mathrm{nm}^{2}$ and 0.0009 $\mathrm{mN} / \mathrm{nm}^{2}$ (Fig. 7, b). For slope $\left(\frac{S}{h_{c}}\right)=0.0007 \mathrm{mN} / \mathrm{nm}^{2}$; $\mathrm{EIT}=\{119.88,124.36,127.68,131.16,135.03,135.63$, $138.48,138.84,138.98,139.24,143.58,144.68,152.59\}$ GPa. For slope $\left(\frac{S}{h_{c}}\right)=0.0008 \mathrm{mN} / \mathrm{nm}^{2}$; EIT $=\{156.06$, 156.26, 156.81, 167.21\} GPa. And, for slope $\left(\frac{S}{h_{c}}\right)=0.0009 \mathrm{mN} / \mathrm{nm}^{2} ;$ EIT $=\{181.02,188.04\} \mathrm{GPa}$ as displayed on the radar with markers(Fig. 7, b). In parallel, histogram (Fig. 7, a) records three distinct steps, the first of $\left(\frac{S}{h_{c}}\right)=0.0007 \mathrm{mN} / \mathrm{nm}^{2}$ spans the interval $[119.88$, 152.59] GPa, the second $\left(\frac{S}{h_{c}}\right)=0.0008 \mathrm{mN} / \mathrm{nm}^{2}$ spans the interval $[156.06,167.21] \mathrm{GPa}$, and the third tier of $\left(\frac{S}{h_{c}}\right)=0.0009 \mathrm{mN} / \mathrm{nm}^{2}$ spans the interval [181.02, 188.04] GPa, where:

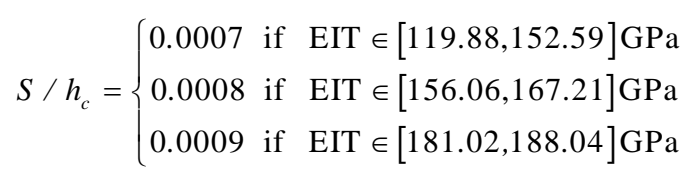

The Eq. (10) shows a proportional relationship between these two parameters.In other words:

$$
\left.\begin{array}{l}
\frac{S}{h_{c}}=(0.0008 \pm 0.0001) \mathrm{mN} / \mathrm{nm}^{2} \\
\text { for EIT } \in[119.88,188.04] \mathrm{GPa} .
\end{array}\right\}
$$

3.4. Confrontation of the slope studied with conventional hardness

Calculating the hardness HIT, is obtained from the ratio of the applied indentation load $P$, the addition of representative area of the imprint, $A$ as follows:

$$
H=\frac{P}{A} \text {. }
$$

The graphical representations of Fig. 8, a, b mentioned below, include the slopes of the calculations, $\left(\frac{S}{h_{c}}\right)_{i}$ vs hardness conventional, HIT, in $\left(\mathrm{mN} / \mathrm{nm}^{2}\right)$.

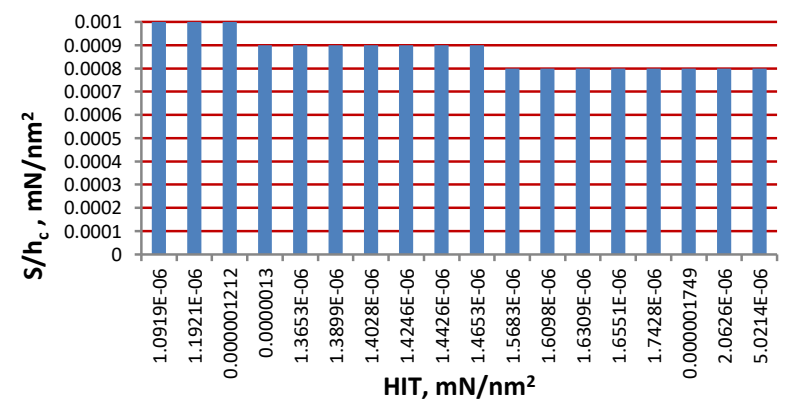

a

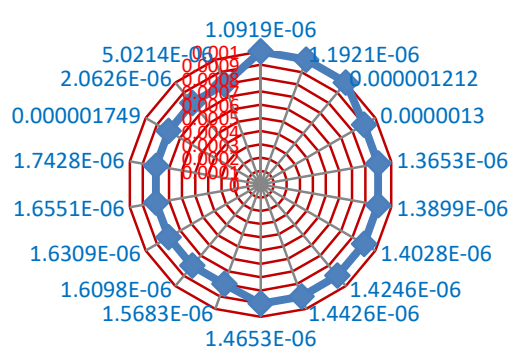

b

Fig. 8 Pointscharacteristics of the slopevs HIT $(a, b)$ 
Graphical representations Fig. 8 (a, b), illustrating the expression of the slope $\left(\frac{S}{h_{c}}\right)$ vs HIT, and highlight the existence of three sets of feature points, placed on orbits: $0.0008 \mathrm{mN} / \mathrm{nm}^{2}, \quad 0.0009 \mathrm{mN} / \mathrm{nm}^{2}$ and $\quad 0.0010 \mathrm{mN} / \mathrm{nm}^{2}$ (Fig. 8, b). For slope $\left(\frac{S}{h_{c}}\right)=0.0008 \mathrm{mN} / \mathrm{nm}^{2}$; hardness $\mathrm{HIT}=\{1568.3,1609.8,1630.9,1655.1,1742.8,1749$, 2062.6, 5021.4 $\} \mathrm{MPa}$. For slope $P t=0.0009 \mathrm{mN} / \mathrm{nm}^{2}$; $\mathrm{HIT}=\{1300,1365.3,1389.9,1402.8,1424.6,1442.6$, 1465.3 MPa. And, for $\left(\frac{S}{h_{c}}\right)=0.0010 \mathrm{mN} / \mathrm{nm}^{2}$; $\mathrm{HIT}=\{1091.9,1192.1,1212\} \mathrm{MPa}$ (Fig. 8, b). In parallel, histogram (Fig. 8, a) records three distinct steps, the first of $\left(\frac{S}{h_{c}}\right)=0.0010 \mathrm{mN} / \mathrm{nm}^{2}$ spans the interval $[1091.9,1212]$ $\mathrm{MPa}$, the second $\left(\frac{S}{h_{c}}\right)=0.0009 \mathrm{mN} / \mathrm{nm}^{2}$ spans the interval $[1300,1465.3] \mathrm{MPa}$, and the third tier of $\left(\frac{S}{h_{c}}\right)=0.0008 \mathrm{mN} / \mathrm{nm}^{2}$ spans the interval $[1568.3,5021.4]$ MPa where:

$$
S / h_{c}=\left\{\begin{array}{l}
0.0008 \text { if } \text { HIT } \in[1568.3,5021.4] \mathrm{MPa} \\
0.0009 \text { if } \text { HIT } \in[1300.0,1465.3] \mathrm{MPa} \\
0.0010 \text { if } \text { HIT } \in[1091.9,1212.0] \mathrm{MPa}
\end{array}\right.
$$

Its deduced that the Eq. (13) of $\left(\frac{S}{h_{c}}\right)$ vs HIT, shows an inverse relationship between these two parameters. On the other hand, the Eq. (13) can be expressed as follows:

$$
\left.\begin{array}{l}
\frac{S}{h_{c}}=(0.0009 \pm 0.0001) \mathrm{mN} / \mathrm{nm}^{2} \\
\text { for EIT } \in[1212,1568.3] \mathrm{GPa} .
\end{array}\right\}
$$

\section{Conclusions}

Nanoindentation tests were conducted to characterize the mechanical properties of brass. We calculated the contact depths, hardnessand modulus of elasticity and rigidity of contact.

Referring to the theory of Oliver and Pharr [1], we are implementing a slope estimation approach to curve $S / h_{c}$ vary in maximum load indentation to express the opposite of projected contact area by linear regression using the least squares method.And we could model the amplitude of $\left(\frac{S / h_{c}}{P_{\max }}\right)=\left(\frac{1}{A_{c}}\right)$ by the aforementioned expression (8). From experimental results, we see that the slope expressing $S / h_{c}$ is constant for a row of loading from $58.35 \mathrm{mN}$ up $3009.85 \mathrm{mN}$, with the exception of some irregularities.

Then, a confrontation between the estimated slope exam and the two key parameters; EIT and HIT, was held to model $S / h_{c}$ depending on other variables studied EIT and HIT. For the first case, the expression (11) showed a proportional relationship between the two variables examined, and constant amplitude of $S / h_{c}$ for an EIT from 119.88 GPa until 188.04 GPa. However, the second case, the expression (13) showed an inversely proportional relationship between the two variables studied, and constant amplitude of $S / h_{c}$ for HIT from 1212.0 GPa until 1568.3 GPa.

This method allowed highlighting a specific point on each material for the mechanical characterization of materials. Looking ahead, we will conduct a comparative study of different materials: Brass, Bronze and Copper to identify the factors explaining the trend characteristic points by Vickers nanoindentation test by using this method.

\section{Acknowledgements}

The author wishes to thank Professor Noureddine BENSEDDIQ for having offered him the opportunity to realize indentation tests Polytechnic IUT of Lille1/ France.

The author gratefully acknowledges Professor Didier CHICOT advice for relevance and quality of leadership within the IUT Polytechnic in the research laboratory of Lille1 / France.

\section{References}

1. Oliver, W.C.; Pharr, G.M. 1992. An improved technique for determining hardness and elastic modulus using load and displacement sensing indentation measurements, Journal of Materials Research 7: 1564-1583. http://dx.doi.org/10.1557/JMR.1992.1564.

2. Ngan, A.H.W.; Wang, H.T.; Tang, B.; Sze, K.Y. 2005. Correcting power-law viscoelastic effects in elasticmodulus measurement using depth-sensing indentation, Int J Solids Struct 42: 1831-1846. http://dx.doi.org/10.1016/j.ijsolstr.2004.07.018.

3. Tang, B.; Ngan, A.H.W. 2003. Accurate measurement of tip-sample contact size during nanoindentation of viscoelastic materials, J Mater Res 18: 1141-1148. http://dx.doi.org/10.1557/JMR.2003.0156.

4. Chicot, D.; Mercier, D. 2008. Improvement in depthsensing indentation to calculate the universal hardness on the entire loading curve, Mech Mater 40: 171-182. http://dx.doi.org/10.1016/j.mechmat.2007.07.002.

5. Chicot, D.; deBaets, P.; Staia, MH.; Puchi-Cabrera, ES.; Louis, G.; Perez Delgado, Y. 2013. Influence of tip defect and indenter shape on the mechanical properties determinationbyindentationofaTiB2-60\% B4C ceramic composite, Inter $\mathrm{J}$ Refract Met Hard Mater 38: $102-110$. http://dx.oi.org/10.1016/j.ijrmhm.2013.01.006.

6. Sahin, O.; Uzun, O.; Kolemen, U.; Uçar, N. 2008. Analysis of ISE in dynamic hardness measurements of $\beta$-Sn single crystals using a depth-sensing indentation technique, Mater Charact 59: 729-736. http://dx.doi.org/10.1016/j.matchar.2007.06.005.

7. VanLandingham, M.R. 2003. Review of instrumented indentation, J Res Nat Inst Stand Techn 108: 249-265. http://dx.doi.org/10.6028/jres.108.024.

8. Pharr, G.M.; Bolshakov, A. 2002. Understanding nanoindentation unloading curves, J Mater Res. 17(10): 2660-2671.

http://dx.doi.org/10.1557/JMR.2002.0386. 
9. Hertz, H. 1896. On the contact of elastic solids, Miscellaneous Papers, Macmillan, London, Chapter 5: 146183.

10. Bulychev, S.I.; Alekhin, V.P.; Shorshorov, M.Kh.; Ternovskii, A.P.; Shnyrev, G.D. 1973. Determining Young's modulus from the indentor penetration diagram, Zavod Lab 39: 1137-1142.

11. Sneddon, I.N. 1965. The relationship between load penetration in the axisymmetric Boussinesq problem for a punch of arbitrary profile, Int J Eng Sci 3: 47-57. http://dx.doi.org/10.1016/0020-7225(65)90019-4.
S. Habibi

STATISTICAL METHODS FOR THE ANALYSIS OF

THE CHARACTERISTIC CURVE OF BRASS BY VICKERS INDENTATION

S u m m a r y

To characterize the mechanical properties of brass, tests by nanoindentation were conducted. The elastic modulus EIT and the hardness HIT are two most important parameters for the evaluation of mechanical properties of materials. Both the modulus and indentation hardness are highly dependent on the stiffness of contact, the contact area and the precision with which they are attached. From experimental results, we see that the slope expressing the rigidity of contact on the contact depth is constant for a row of loading from $58.35 \mathrm{mN}$ up $3009.85 \mathrm{mN}$, with the exception of some irregularities. T hereafter, we modelled the mechanical behaviour of this slope by the use of linear regression by least squares method. In the final part of this paper, a review of confrontation between the estimated slope and the two key parameters; the indentation modulus and hardness of conventional, was held to identify the factors explaining the trend characteristic points by Vickers nanoindentation test.

Keywords: nanoindentation, characterization, contact stiffness, contact depth, modelling, statistics.

Received August 28, 2015

Accepted November 25, 2016 